\title{
AN EMPIRICAL ANALYSIS OF CONSUMPTION EXPENDITURE IN CHINA:A CASE STUDY OF CHANGCHUN CITY
}

\author{
Wenliang $\mathrm{Lu}^{*}$ \\ Reitaku University \\ Sim-Yee Lau \\ Reitaku University
}

\begin{abstract}
This paper conducted a case study on Changchun - a city with 7.6 million populations located in the northeastern part of China - that analyzes consumer behavior in China. The empirical analysis is based on the AIDS model propounded by Deaton and Muellbauer (1980). The data used in this econometric analysis is a time series cross sectional panel data from 300-household survey responses collected from January 2009 to December 2011. The empirical results show that "food" and "education, culture and recreation" are necessity goods for the people in Changchun. These two items cover $44 \%$ of total expenditure share in the data set. At the same time, these two items are Giffen goods because their expenditure share increases even with rise in their prices. The findings suggest that "housing" is a luxury good but it is also a Giffen good. From this point, it is plausible to argue that the growth of real income across China in general and in Changchun in particular has been lagging behind the rise in prices of "housing". Additionally the estimated own-price elasticity of demand in "education, culture and recreation" suggests that people in Changchun will spend more on these items in order to acquire a higher quality of education despite price increases. The estimated compensated cross-price elasticity of demand of various pairs of goods like "food and housing," "food and education, culture and recreation," "clothing and housing," "clothing and medical" and others indicate that the theoretical assumption of a diminishing MRS does not hold for our data set. The analytical results show that people's demand in "medical" is not being influenced by its price and people's disposable income.
\end{abstract}

Keywords: AIDS; Income Elasticity Of Demand; Cross-Price Elasticity Of Demand; Compensated Cross-Price Elasticity Of Demand; Net Substitute Goods; Net Complement Goods.

Corresponding author: Graduate School of Economics and Business Administration, Reitaku University 2-1-1 Hikarigaoka, Kashiwa-shi, Chiba-ken, Japan. Email: luke_mysky@hotmail.com 


\section{INTRODUCTION}

Since the launch of reform and the open door policy in 1979, China's economy has grown impressively. Gross national income (GNI) per capita in PPP (in current international dollar) grew from $\$ 1,360$ in 1993 to $\$ 11,850$ in 2013. Presently, China is not only the largest world production center for a broad spectrum of products but it has also gradually emerged as one of the largest markets for goods and services in the world economy.

Indeed, the sharp growth of people's income has brought the transition of consumption pattern and consumption level. Mitsubishi UFJ Research and Consulting (2012) estimated that China's household expenditure in consumers' goods was about $\$ 2,055$ billion in 2012 and that figure is predicted to grow to $\$ 4,000$ billion in 2020. Empirical research on household expenditure of China has attracted substantial attention in academic policy-making and business communities. Nevertheless, the empirical works on Chinese consumer behaviors are still inadequate. Therefore, against this background, this paper conducts a case study of Changchun City (hereafter Changchun) in terms of how changes in prices of a set of consumers' goods affect the consumers' demand of those sets of goods vis-à-vis their disposable income.

Changchun is the capital and the largest city of Jilin Province in northeastern part of China. Including its suburban areas, Changchun has about 7.6 million inhabitants. In 2012, Changchun's per capita GDP was 57,594 RMB (about \$9,200), about 1.5 times of national level $(38,354 \mathrm{RMB})$ but about 0.8 of that in Shanghai $(73,297 \mathrm{RMB})^{1}$. We chose Changchun as the object of this empirical research due to three relevant points. Firstly, the disposal income of Changchun's people is close to the average level of Chinese urban areas. Secondly, Changchun typically represents the economic development pattern of China that investment and exports have been the twin engines of economic growth. Thirdly, we have acquired a Changchun's household survey data set comprising 300 households from January 2009 to December 2011. The survey sample size is appropriate in terms of the size of Changchun's population. By all accounts, Changchun is the microcosm of rapid economic growth of China. So through taking Changchun as a case study for analysing consumer behaviour, we can observe some general characteristics in China.

The rest of this paper is organized as follows. Next session provides a literature review that covers key theoretical foundations of consumer behaviors and other existing literature associated with the scope of this study. Session 3 provides the analytical framework that explains our data set, model specification and estimation method. Session 4 shows the analytical findings and discussions. Session 5 concludes this paper.

\section{LITERATURE REVIEW}

Empirical studies on demand analysis have been accumulated along with the sophistication of methodologies for estimating elasticity of demand in terms of income and price changes. Stone (1954) was the pioneer in formulating a specification in estimating a system of demand equations in real income and real prices consistent with the theory of consumer behavior.

National Bureau of Statistics of China (2013). 
That specification is based on a double-log demand function. Expressing in log form, the dependent variable is the demand quantity of commodity $x_{i}$ while the independent variables comprise disposable income $\mathrm{Y}$ and each respective price of $x_{i}$. This specification facilitates the estimation of income elasticity of demand and cross-price elasticity of demand for good $\mathrm{i}$ with respect to good $\mathrm{j}$ (own-price elasticity of demand for any $\mathrm{i}=\mathrm{j}$ ).

Stone's seminal work has inspired many other forms of model specification in estimating a liner demand system. Barnett (1979) shows that the Rotterdam Model is of relevancy in addressing demand aggregation in the framework of general equilibrium analysis. Deaton and Muellbauer (1980) develop a model known as Almost Ideal Demand System (AIDS) which essentially is represented by transforming independent variables (real disposable income and prices of each good) into logarithm form. This model allows estimation of income elasticity of demand (or expenditure elasticity of demand) and cross-price elasticity of demand for good $\mathrm{i}$ and good $\mathrm{j}$ (own-price elasticity for any $\mathrm{i}=\mathrm{j}$ ) for a given set of expenditure shares. This model satisfies two important properties of a demand function viz. homogeneity and additive. In addition, this model also holds the property of symmetry with regard to the coefficients to be estimated. In order to derive a direct estimation of compensated elasticity, Alston, Chalfant and Poggott (2002) show that by using a double-log demand model instead of AIDS (which is specified in a single-equation form), it is able to estimate compensated elasticity of demand directly by deflating income using Stone's price index. By doing so, the right hand side of this modified model is the same as that in AIDS.

Wakabayashi (2001) analyzed household final consumption expenditure in Japan based on data collected from National Consumer Survey across 47 prefectures in Japan in 1984, 1989, 1994. This data-set was then compiled into 13 age groups (from less than 24 years old to more than 75 years at 5 years interval). In spite of using AIDS specification, this study did not examine the difference between uncompensated and compensate cross-price elasticity of demand. The analysis could have addressed issues such as if the analysis had focused on how households behaved to price changes with respect to the change in income and also with regard to how if households' utilities were held constant with the change in real income.

Tachibanaki and Imayama (1999) conducted a time series empirical analysis of the changes in consumer behavior in Japan, Taiwan and Thailand, which was based on the specification of Stone's demand function. Though this empirical work has contributed to a better understanding of how consumer behaviors have changed in the process of economic development, it did not identify if goods were net substitutes or net complements. Their analytical focus was on uncompensated elasticity of demand which only implies gross substitutes and gross complements. For this reason, therefore this study did not clarify which demand was affected by the change in price of which particular goods.

Jin Fan (2004) analyzed the diversity of consumption behavior out of income by building up an AIDS model of Chinese rural residents, classified into five groups by income. This empirical research just gave a conclusion that the income has a crucial effect on consumption in a rural area, without an original finding. In comparison, Yang (2009) used his estimated consumption function to highlight the features of marginal propensity to consume of the low- 
income stratum, the middle-income stratum and the high-income stratum in China. He alleged that income disparity in urban areas and between urban and rural areas can be mitigated by government interventions in enlarging the population of the middle-income stratum. This implication is quite unclear because even within urban areas there are different income groups in terms of consumption expenditure. Additionally, from the analytical findings of Nolintha and Lau (forthcoming), asset ownerships differ between urban-rural and asset gaps exist inside urban and rural areas. Inequality can be mitigated if government targets its interventions at within-group inequality to narrow the inequality gap in consumption expenditure but for the case of inequality in assets the measures would have to be targeted at between-group inequality.

By and large, empirical studies on the consumer behavior are well documented. However, in connection to key household consumption items (viz. "food", "clothing", "household utensils", "housing", "medical care", "transportation and communication", "education, culture and recreation", "other expenditure") in China, a few relevant questions may be asked. Do consumers purchase these goods only when they need them? And how do income and prices affect consumer behavior in China? Both of these problems have not been adequately explored. In order to compensate for this lack of empirical evidences, this study intends to reveal the actual condition of household consumption in China. By choosing Changchun as a case study, this study intends to analyze the actual conditions of consumer behavior in urban areas of China using income and expenditure data collected from household surveys conducted in Changchun.

\section{ANALYTICAL FRAMEWORK}

\subsection{Data}

This study uses a household survey data set from Changchun. This data set contains 300 households' responses with regard to disposable income, total consumption expenditure, consumers expenditure in eight groups viz. "food", "clothing," "household utensils," "housing," "medical care," "transportation and communication," "education, culture and recreation," and "other expenditures." The responses were collected from January 2009 to December 2011. Thus, a panel data for this period is constructed from this data set.

Because monthly prices in Changchun City from January 2009 to December 2011 were not available, we used monthly prices of each expenditure item compiled by Jilin provincial statistical bureau ${ }^{2}$. In addition, this study uses the monthly consumer price index (CPI) of Jilin provinces to compute real disposable income in this data set.

Table 1 summarizes the descriptive statistics of a time series cross sectional data set. Monthly mean value of each variable in this panel data set is 4,416 RMB for disposable income, 3,602 RMB for consumption expenditure, 1,130 RMB for "food", 569 RMB for "clothing", 317 RMB for "household

National Bureau of Statistics of China (2011). 
Table 1 summarizes the descriptive statistics of a time series cross sectional data set. Monthly mean value of each variable in this panel data set is 4,416 RMB for disposable income, 3,602 RMB for consumption expenditure, 1,130 RMB for "food", 569 RMB for "clothing", 317 RMB for "household utensils", 557 RMB for "housing", 585 RMB for "medical care", 482 RMB for "transportation and communication", 754 RMB for "education, culture and recreation", 229 RMB for "other expenditure."

Table 1: Descriptive Statistics (in RMB)

\begin{tabular}{|c|c|c|c|c|c|c|c|c|c|c|c|}
\hline Year & & 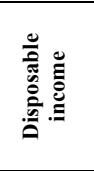 & 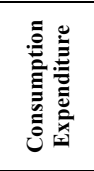 & $\begin{array}{l}\overrightarrow{0} \\
\stackrel{0}{0} \\
\text { In }\end{array}$ & 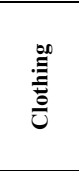 & 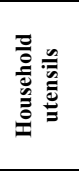 & 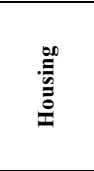 & 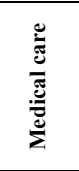 & 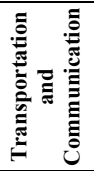 & 豆总 & 冚 \\
\hline \multirow[t]{5}{*}{2009} & Mean & 3,957 & 3,169 & 1,052 & 473 & 744 & 465 & 564 & 401 & 751 & 203 \\
\hline & Maximum & 54,896 & 132,904 & 11,410 & 18,000 & 7,499 & 22,087 & 53,140 & 130,846 & 31,170 & 16,381 \\
\hline & Minimum & $-8,127$ & 317 & 95 & 1 & 1 & 3 & 2 & 2 & 1 & 2 \\
\hline & Standard deviation & 2,498 & 3,899 & 634 & 781 & 1,204 & 1,048 & 1,838 & 2,704 & 2,005 & 666 \\
\hline & Sample size & 3,600 & 3,600 & 3,600 & 2,845 & 202 & 2,926 & 2,445 & 3,388 & 1,905 & 2,926 \\
\hline \multirow[t]{5}{*}{2010} & Mean & 4,402 & 3,534 & 1,139 & 567 & 272 & 552 & 529 & 438 & 736 & 204 \\
\hline & Maximum & 37,917 & 102,336 & 12,527 & 14,000 & 14,823 & 24,110 & 40,432 & 100,996 & 90,904 & 16,030 \\
\hline & Minimum & $-6,319$ & 254 & 105 & 1 & 1 & 2 & 1 & 2 & 0 & 1 \\
\hline & Standard deviation & 2,692 & 3,845 & 729 & 822 & 806 & 1,085 & 1,590 & 2,235 & 2,437 & 613 \\
\hline & Sample size & 3,597 & 3,600 & 3,600 & 2,834 & 2,970 & 2,606 & 2,186 & 3,291 & 2,153 & 2,865 \\
\hline \multirow[t]{5}{*}{2011} & Mean & 4,890 & 4,103 & 1,200 & 672 & 332 & 670 & 661 & 610 & 772 & 291 \\
\hline & Maximum & 101,541 & 508,171 & 20,152 & 81,922 & 52,160 & 133,144 & 63,920 & 150,253 & 78,496 & 75,168 \\
\hline & Minimum & $-22,610$ & 86 & 10 & 1 & 0 & 3 & 1 & 1 & 1 & 1 \\
\hline & Standard deviation & 4,269 & 10,212 & 904 & 1,962 & 1,292 & 3,042 & 2,373 & 4,118 & 2,683 & 1,981 \\
\hline & Sample size & 3,589 & 3,600 & 3,598 & 2,701 & 3,063 & 2,501 & 2,227 & 3,255 & 2,334 & 2,366 \\
\hline \multirow[t]{5}{*}{ All sample } & Mean & 4,416 & 3,602 & 1,130 & 569 & 317 & 557 & 585 & 482 & 754 & 229 \\
\hline & Maximum & 101,541 & 508,171 & 20,152 & 81,922 & 52,160 & 133,144 & 63,920 & 150,253 & 90,904 & 75,168 \\
\hline & Minimum & $-22,610$ & 86 & 10 & 1 & 0 & 2 & 1 & 1 & 0 & 1 \\
\hline & Standard deviation & 3,272 & 6,700 & 767 & 1,297 & 1,088 & 1,915 & 1,960 & 3,116 & 2,414 & 1,196 \\
\hline & Sample size & 10,786 & 10,800 & 10,798 & 8,380 & 6,235 & 8,033 & 6,858 & 9,934 & 6,392 & 8,157 \\
\hline
\end{tabular}

Table 2: Mean expenditure share with respect to disposable income

\begin{tabular}{lccc}
\hline & Obs. & Mean & Std. Err. \\
\hline Food & 10,798 & 0.3101 & 0.0073 \\
Clothing & 8,380 & 0.1247 & 0.0051 \\
Household utensils & 6,235 & 0.0777 & 0.0060 \\
Housing & 8,033 & 0.1048 & 0.0062 \\
Medical care & 6,858 & 0.1042 & 0.0063 \\
Transportation and communication & 9,934 & 0.1020 & 0.0046 \\
Education, culture and recreation & 6,392 & 0.1317 & 0.0079 \\
Other expenditure & 8,157 & 0.0448 & 0.0027 \\
\hline
\end{tabular}

Table 2 tabulates mean expenditure share of each respective group of goods with respective to disposable income. In this panel data set, the highest monthly mean expenditure share is "food" which is 31 percent of disposable income. It is followed by "education, culture and recreation" (13.2 percent), "clothing" (12.5 percent), "housing" (10.5 percent), "medical care" (10.4 percent), "transportation and communication" (10.2 percent), "household utensils" (7.8 percent), "other expenditure" (4.5 percent). 


\subsection{Model Specification}

For estimating the household consumption expenditure, we use the Almost Ideal Demand System (AIDS) expounded by Deaton-Muellbauer (1980). The specification as shown in Equation 1.

$$
w_{i}=\operatorname{con}+\varepsilon_{i} \log \left(\frac{x}{p}\right)+\sum_{j} \gamma_{i j}^{c} \log \left(P_{j}\right)
$$

$w_{i}$ denotes the share of expenditure in category $\mathrm{i}$ with respect to disposable income $x . P$ is the monthly CPI and $P_{j}$ is the monthly price for each respective category. $\varepsilon_{i}$ and $\gamma_{i j}^{c}$ is income elasticity of demand for good $\mathrm{i}$ and compensated cross-price elasticity for goods $\mathrm{i}$ and $\mathrm{j}$, respectively. Compensated cross-price elasticity of demand shows how a consumer's demand for a good changes when its price changes while holding the consumer's utility constant. Because of keeping a consumer's utility at the same level (i.e., on the same indifference curve) when a price changes, that consumer would have to adjust his/her real income so as to compensate that change in expenditure ${ }^{3}$.

Essentially, similar to other empirical studies like Nakano, Suzuki and Washizu (2008) and Koike (2011), Equation 1 satisfies the properties of the linear restrictions in additive, homogeneity and symmetry on fixed parameters. These properties are shown below.

$$
\begin{gathered}
\sum_{i=1}^{n} \text { cons }=1, \sum_{i=1}^{n} \varepsilon_{i}=1, \sum_{i=1}^{n} \gamma_{i j}=1 \\
\sum_{j} \gamma_{i j}=0 \\
\gamma_{i j}=\gamma_{j i}, \forall i, j
\end{gathered}
$$

From Slutsky equation, as documented in Izumida, Ishi, Kimura and Igarashi (2006), $\gamma_{i j}^{c}$ is the sum of cross-price elasticity of demand and the product of income elasticity of demand and the share of expenditue in good with respect to disposable income.

\subsection{Estimation Method}

Our estimation is based on the first-order autoregressive model (AR(1)) for panel data with fixed effects $(\mathrm{FE})^{4}$. The time series cross sectional panel data from household survey responses were from January 2009 to December 2011. Kruiniger (2002) suggests that time series cross-

\footnotetext{
The compensated cross-price elasticity of demand is also known as Hicksian compensated elasticity of demand. Contrary, the Marshallian elasticity of demand shows how a demand for a good changes when its own price or prices of other good have changed while nominal income is constant.

4 For details, see Greene (2000), pp. 557-589.
} 
sectional panel data estimation with FE brings about consistent estimators for it incorporates "individual" effects that are unobservable but may give bias to the predictors. In other words, FE eliminates time-invariant characteristics which may be correlated with the observable variables ${ }^{5}$.

We conduct our estimations in two stages. Firstly, we estimate those parameters specified in Equation 1 (cons, $\varepsilon_{i}, \gamma_{i j}^{c}$ ). Secondly, we use our estimated income elasticity of demand $\left(\varepsilon_{i}\right)$ and compensated cross-price elasticity of demand $\left(\gamma_{i j}^{c}\right)$ that are statistically significance, to estimate cross-price elasticity of goods $\mathrm{i}$ to goods $\mathrm{j}\left(\gamma_{i j}\right)$. Their relationship is shown in Equation $5^{6}$. After that, we conducted one-sample $\mathrm{t}$ tests for all estimations $\gamma_{i j}$ to determine the validity of our analytical results.

$$
\gamma_{i j}=\gamma_{i j}^{c}-\varepsilon_{i} w_{i}
$$

If $\varepsilon_{i}$ is more than zero this indicates a luxury good, whereas if $\varepsilon_{i}$ is less than zero it refers to a necessity good. A luxury good is a good in which its demand increases more than proportionally with the increase in disposable income. By contrast, a necessity good is a good in which its demand increases less than proportionally with the rise in disposable income.

\section{ANALYTICAL RESULT AND DISCUSSION}

\subsection{Income Elasticity of Demand}

Table 3 shows that income elasticity of demand for food (a necessity good) is -0.0118 which implies that expenditure share in "food" reduces $0.01 \%$ when disposable income increased by $1 \%$. Notwithstanding, according to Engel's law and also taking into consideration of continuous economic growth in China, it is reasonable to predict that the share of food expenditure will shrink as disposable income rises in Changchun.

Likewise, the estimated income elasticity of demand for "education, culture and recreation" is -0.0133 and thus it indicates this expenditure item is a necessity good. Its expenditure share reduces $0.01 \%$ when disposable income is increased by $1 \%$ t. The income elasticity of demand for this expenditure item is low because of the availability of compulsory education. At the same time, it is also quite plausible to explain that price (income) sensitivity is low for education in Changchun because parents are willing to pay higher education fees (either in-school or outof-school tuition or even both) for a better quality of education. This characteristic is widely observed across China.

\footnotetext{
5 Let $y_{i j}=a+b x_{i t}+\varepsilon_{i j}$, the error term is represented by $\varepsilon_{i j}=m_{i}+n_{i j}$, if $m_{i}$ is correlated with $x_{i t}$ with $x_{i t}\left(m_{i}\right.$ is not correlated with $\left.x_{i t}\right)$, then $E\left(m_{i} x_{i t}\right)=\operatorname{Cov}\left(m_{i}, x_{i t}\right) \neq 0$

6 This formulation is expanded from Slutsky Equation in terms of elasticity.
} 
On the other hand, "household utensils," "housing" and "transportation and communication" are luxury goods for people in Changchun. Also, the expenditure share of "household utensils" is the most sensitive but that of "transportation and communication" is the least sensitive to variation of disposable income.

Income elasticity of demand for "clothing", "medical care" and "other expenditure" is statistically insignificant, respectively. Thus their income elasticities of demand are zero ( $\mathrm{o}$ : $\varepsilon_{i}=0$ ), which implies that the rise in disposable income does not affect the changes of demand in these goods. It is plausible that demand for these three sets of goods in Changchun is fixed. The classification in terms of necessity goods and luxury goods for the estimated income elasticity of demand is tabulated in Table 4.

Table 3: Estimated income elasticity of demand

\begin{tabular}{lcccc}
\hline & $\begin{array}{c}\text { Income } \\
\text { elasticity }\end{array}$ & Std. err. & t-value & \\
\hline Food & -0.0118 & 0.0055 & -2.14 & $* *$ \\
Clothing & 0.0021 & 0.00383 & 0.54 & $* * *$ \\
Household utensils & 0.0147 & 0.0075 & 1.96 & $*$ \\
Housing & 0.0128 & 0.0043 & 3.00 & $* *$ \\
Medical care & 0.0029 & 0.0051 & 0.57 & $* *$ \\
Transportation and communication & 0.0061 & 0.0031 & 1.98 & \\
Education, culture and recreation & -0.0133 & 0.0057 & -2.31 & 0.89 \\
Other expenditure & 0.0021 & 0.0023 & 0.39 & \\
\hline
\end{tabular}

Note: *: t-statistics at $1 \%$ significant level; **: t-statistics at $5 \%$ significant level; ***: t-statistics at $10 \%$ significant level.

Table 4: Interpretation of estimated income elasticity of demand

\begin{tabular}{|c|c|c|c|c|c|c|c|}
\hline Food & Clothing & $\begin{array}{c}\text { Household } \\
\text { utensils }\end{array}$ & Housing & $\begin{array}{c}\text { Medical } \\
\text { care }\end{array}$ & $\begin{array}{c}\text { Transportation \& } \\
\text { communication }\end{array}$ & $\begin{array}{l}\text { Education, culture } \\
\text { and recreation }\end{array}$ & $\begin{array}{c}\begin{array}{c}\text { Other } \\
\text { expenditure }\end{array} \\
\end{array}$ \\
\hline NG & - & LG & LG & - & LG & NG & \\
\hline
\end{tabular}

\subsection{Own-price Elasticity of Demand}

We applied the estimated results of Equation 1 into Equation 5, then used one-sample t-test to derive the coefficients of uncompensated or simply Marshallian own- and cross-price elasticity of demand for good $\mathrm{i}$ and good $\mathrm{j}$. Table 5 summarizes those results.

Uncompensated own-price elasticity of demand for "food," "household utensils," "housing," "transportation and communication," "education, culture and recreation" is $0.6532,-0.001$, $-1.2623,-0.0007,3.4484$, respectively. Expenditure share in "clothing", "transportation and communication" is respectively inelastic to change in its own price. This means even if the 
price of "clothing" and "transportation and communication" has increased respectively, the expenditure share of its own does not change significantly. The expenditure share of "food" increases $0.7 \%$ with about $1 \%$ hikes in "food" prices. Expenditure share in "housing," "education, culture and recreation" is respectively elastic to change within its own price. A $1.3 \%$ rise in expenditure share in "housing" is caused by $1 \%$ of its own price reduction. Conversely, $3.4 \%$ rise in expenditure share in "education, culture and recreation" is caused by $1 \%$ of price increase of its own. As shown in Table 5, uncompensated own-price elasticity of demand for "clothing", "medical care" and "other expenditure" is zero, respectively. This means the change in each respective set of goods does not change its own expenditure share.

Table 5: Estimated uncompensated cross price elasticity of demand

\begin{tabular}{|c|c|c|c|c|c|c|c|c|}
\hline & \multicolumn{8}{|c|}{$\mathbf{j}$} \\
\hline & 1 & 2 & 3 & 4 & 5 & 6 & 7 & 8 \\
\hline$\gamma_{1 j}$ & 0.6532 & 0.005 & 0.0008 & 1.229 & 0.0015 & -2.3956 & 4.3334 & -3.9328 \\
\hline $\mathrm{t}$ & $2.60 \mathrm{E}+04$ & 198.88 & 47.59 & $5.80 \mathrm{E}+04$ & 60.24 & $-1.70 \mathrm{E}+05$ & $1.70 \mathrm{E}+05$ & $-1.60 \mathrm{E}+05$ \\
\hline$\gamma_{2 j}$ & 0 & 0 & 0 & 0 & 0 & 0 & 0 & 0 \\
\hline$\gamma_{3 j}$ & -0.0062 & -0.0023 & -0.001 & -0.0021 & -0.0019 & 2.3148 & -2.065 & -0.0008 \\
\hline $\mathrm{t}$ & $-2.00 \mathrm{E}+02$ & -76.7 & -47.59 & -77.31 & -60.24 & $1.30 \mathrm{E}+05$ & $-6.60 \mathrm{E}+04$ & -60.4 \\
\hline$\gamma_{4}$ & -0.0054 & 0.9081 & -0.0009 & -1.2623 & -1.4627 & 1.7156 & -0.002 & 2.5773 \\
\hline $\mathrm{t}$ & $-2.00 \mathrm{E}+02$ & $3.50 \mathrm{E}+04$ & -47.59 & $-5.50 \mathrm{E}+04$ & $-5.30 \mathrm{E}+04$ & $1.10 \mathrm{E}+05$ & -70.568 & $2.30 \mathrm{E}+05$ \\
\hline$\gamma_{5 j}$ & 0 & 0 & 0 & 0 & 0 & 0 & 0 & 0 \\
\hline$\gamma_{6 j}$ & -0.0026 & -0.00096 & -0.0007 & -0.0009 & -0.0008 & -0.0007 & -0.0009 & -0.0003 \\
\hline $\mathrm{t}$ & $-2.00 \mathrm{E}+02$ & -76.7 & -95.56 & -77.31 & -60.24 & -95.56 & -70.57 & -60.4 \\
\hline$\gamma_{7 j}$ & -0.3977 & 0.0021 & 0.0009 & 0.0019 & 0.0017 & 1.9379 & 3.4484 & 1.8166 \\
\hline $\mathrm{t}$ & $-1.40 \mathrm{E}+04$ & 76.7 & 47.59 & 77.31 & 60.24 & $1.20 \mathrm{E}+05$ & $1.20 \mathrm{E}+05$ & $1.50 \mathrm{E}+05$ \\
\hline$\gamma_{8 j}$ & 0 & 0 & 0 & 0 & 0 & 0 & 0 & 0 \\
\hline
\end{tabular}

Notes: for $\mathrm{j}, 1=$ food, $2=$ clothing, $3=$ household utensils, $4=$ housing, $5=$ medical care, $6=$ transportation and communication, $7=$ education, culture and recreation, $8=$ other expenditure; " 0 " is because the estimated income elasticity and compensated income elasticity (Equation 5) was statistically insignificance $\left(H_{0}: \gamma_{i j}^{c}=0, H_{0}: \varepsilon_{i}=0\right)$, respectively; “t” denotes t-value.

\subsection{Uncompensated Cross-price Elasticity of Demand}

The uncompensated cross-price elasticity of demand for "food" and "clothing," "household utensils," "housing," "medical care," "transportation and communication," "education, culture and recreation," "other expenditure" is $0.005,0.0008,1.229,0.0015,-2.3956,4.334,-3.9328$, respectively. These results suggest that "food-clothing," "food-housing utensils," "foodhousing," "food-medical care," "food-education, culture and recreation" are gross substitutes. "Food" and "transportation and communication," "food" and "other expenditure" are gross complements. "Food-clothing," "food-household utensils," and "food-medical care" are inelastic, but "food-housing," "food-transportation and communication," and "food-education, culture and recreation" are elastic.

Except "transportation and communication," uncompensated cross-price elasticity of demand for "household utensils" and other expenditure item is negative, respectively. These results mean that "household utensils" and "transportation and communication" are gross substitutes. 
Whereas all other pairs of goods are gross complements. Furthermore, "household utensilstransportation and communication" and "household utensils-education, culture and recreation" are very elastic $(2.3148,-2.065$, respectively) while others are inelastic (Table 5).

"Housing-food", "housing-household utensils", "housing-medical care", "housing-education, culture and recreation" are gross complements. Among them, "housing-medical care" is elastic (-1.4627). On the other hand, "housing-transportation and communication", "housing-other expenditure" are gross substitutes and elastic (1.7156, 2.5773, respectively).

For "transportation and communication", its uncompensated cross-price elasticity of demand with other goods are negative and thus all pairs of goods are gross complements. Furthermore, all pairs are extremely insensitive to price changes.

Uncompensated cross-price elasticity of demand for "education, culture and recreation" with other goods are positive except for "food." By implication, "education, culture and recreation" and "food" are gross complements but other pairs are gross substitutes. Furthermore, "education, culture and recreation-transportation and communication" and "education, culture and recreation-other expenditure" are sensitive to price changes (1.9379, 1.8166, respectively).

\subsection{Compensated Own-price Elasticity of Demand}

The estimated results of compensated cross-price elasticity of demand for good $\mathrm{i}$ and good $\mathrm{j}$ are summarized in Table 6. The compensated own-price elasticity $\left(\gamma_{i j}^{c}, \mathrm{i}=\mathrm{j}\right)$ of demand for "food," "clothing," "housing,"“education, culture and recreation" is respectively statistically significant. Holding utility constant, the compensated own-price elasticity of demand for "food" is 0.6482 . This means a consumer raises his/her expenditure share in food by $0.65 \%$ when its price increases $1 \%$. Food's compensated own-price elasticity of demand (substitution effect) comprises 0.6542 substitution effect and -0.004 of income effect. Because substitution effect is greater than income effect, food items are Giffen goods in this data set ${ }^{7}$. The period of household survey of our data set was from January 2009 to December 2011 when in the same period food prices in China were affected by food commodities speculation. Figure 1 depicts the rise of food prices from the middle of 2009. The price increase in food has generated more demand. This is because in order to keep utility constant, the drop in real disposal income (income effect) is compensated by the substitution effect.

As for "housing," its compensated own-price elasticity of demand is -1.2604 . This means that expenditure in "housing" decreases $1.26 \%$ when its own price increases by about $1 \%$. Also this compensated own-price elasticity is less than zero because it is the sum of uncompensated

From the Slutsky equation, compensated own-price elasticity of demand (the substitution effect) is the sum of uncompensated ownprice elasticity of demand and the product of income elasticity of demand and share of the good's expenditure (which is the income effect). If substitution effect is greater than income effect, then it is a normal good. A normal good is a good when consumer's income increases its demand increase. If the sum of substitution effect (SE) and income effect (IE) is negative but $|S E|>|I E|$ (i.e., $\mathrm{SE}>\mathrm{IE}$ or $\mathrm{SE}<-\mathrm{IE}$ ), then it is an inferior good. An inferior good is a good that decreases in demand when the income rises. On the other hand, if the sum of substitution effect (SE) and income effect (IE) is positive but $|S E|>|I E|$ (i.e., -IE $<\mathrm{SE}<\mathrm{IE}$ ), then it is a Giffen good. A Giffen good is a good that demand increases when its price rises. 


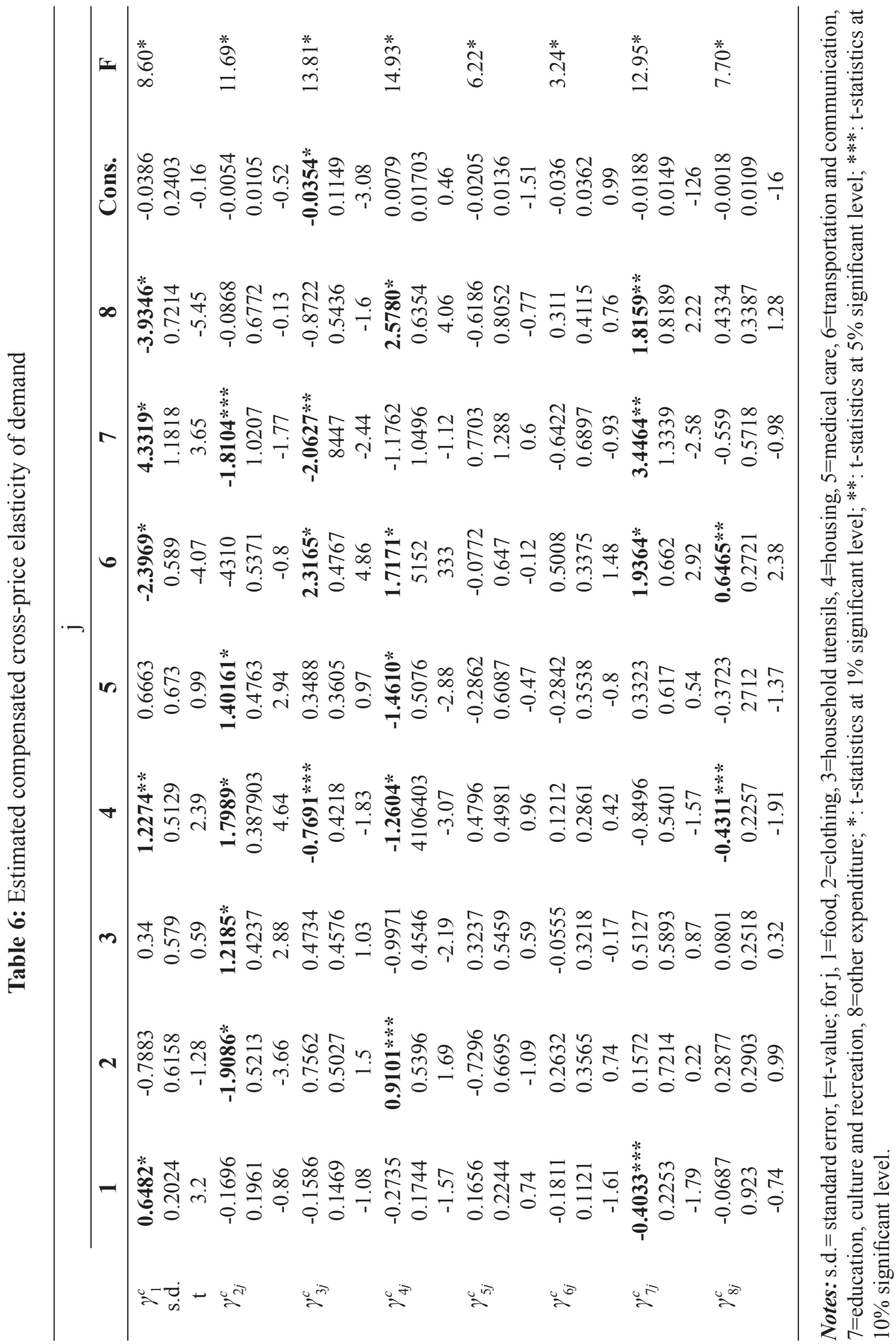


Figure 1: Prices of Expenditure Items (January 2009 to December 2011)

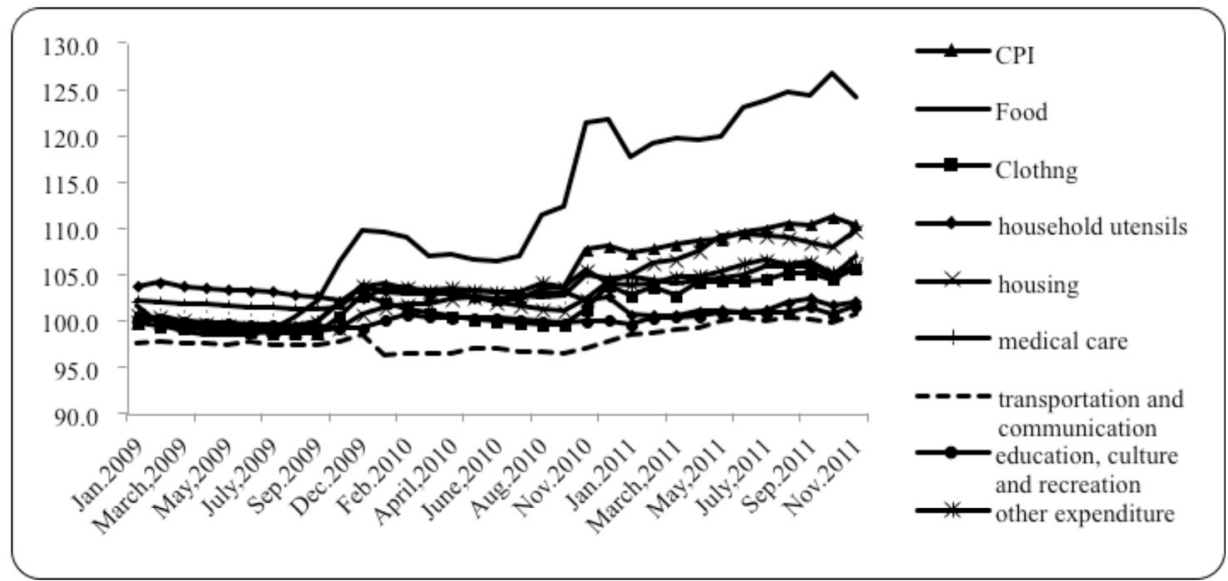

Source: Compiled from Jilin Statistical Yearbook 2011

own-price elasticity of demand (-1.2623) and income effect (0.001). Thus "housing" is a Giffen good. This result is not surprising in the observed reality in China in general, the demand for housing continues to increase even when its price is increasing. It is suggested that this phenomenon occurs because Chinese believe demand outstrips supply and thus the value of housing will continue to rise over a long period of time. As such, the people of Changchun also behave in this manner.

For expenditure share in "education, culture and recreation," the compensated own-price elasticity of income is 3.4464 . This suggests that expenditure share increases by $3.45 \%$ when its price increases by about $1 \%$. The sum of substitution effect and income effect is positive but the former (3.4464) is greater than the latter (-0.002). This means this item is also a Giffen good. Although the demand for "education, culture and recreation" is negative (a necessity good) but inelastic to the change in disposable income, it can be contended that people in Changchun spend more on this expenditure item in order to get a higher quality of education even if its price increases.

Although the compensated own-price elasticity of demand for "clothing" is $-1.9086(1 \%$ statistically significance) but its income effect is zero because income elasticity of demand for "clothing" is not statistically significant ${ }^{8}$. This means the expenditure share in "clothing" decrease 1.91 units if its price increases about 1 unit. The compensated own-price elasticity of demand for "household utensils," "medical care," "transportation and communication" and "other expenditure" are all statistically insignificant. These results suggest that expenditure share in each respective good remains the same even if its own prices changes. However, because the sum of substitution effect and income effect for "household utensils" and "transportation and communication" is respectively in negative value (-0.001 for each item), these two groups are normal goods.

$8 H_{\mathrm{o}}: \varepsilon_{i}=0$ is not statistically rejected. 


\subsection{Compensated Cross-price Elasticity of Demand}

The estimated compensated cross-price elasticity of demand for "food-housing," "foodtransportation and communication," "food-education, culture and recreation" and "foodother expenditure" is 1.2274, -2.3969, 4.3319 and -3.9346, respectively9. By implication, "food-housing," "food-education, culture and recreation" are net substitute goods, but "foodtransportation," "food-other expenditure" are net complementary goods. Put differently, when the price of "housing" and "education, culture and recreation" increases $1 \%$ then expenditure share increases $1.2 \%$ and $4.3 \%$, respectively. Conversely, when the price of "transportation and communication" and "other expenditure" increases by $1 \%$ then the expenditure share in "food" decreases $2.4 \%$ and $3.9 \%$, respectively.

Compensated cross-price elasticity of demand for "clothing-household utensils," "clothinghousing," "clothing-medical care," "clothing-education, culture and recreation" is 1.2185 , 1.7989, 1.4016, -1.8104 , respectively. These findings suggest "clothing-household utensils," "clothing-housing" and "clothing-medical care" are net substitute goods, respectively, but "clothing-education, culture and recreation" are net complementary goods. For the net substitute goods, it is apparent that when the prices of other goods like "household utensils", "housing" and "medical care" rise about $1 \%$ then each corresponding expenditure share in "clothing" increases $1.2 \%, 1.8 \%, 1.4 \%$. However, the expenditure share in "clothing" reduces $1.81 \%$ when the price of "education, culture and recreation" increases about $1 \%$.

For the expenditure in "household utensils," its compensated cross-price elasticity of demand with respect to "housing," "transportation and communication," "education, culture and recreation" is $-0.7691,2.3165,-2.0627$, respectively. These indicate that "household utensilshousing," "household-education, culture and recreation" are net complementary goods, but "household utensils-transportation and communication" are net substitute goods. These estimated coefficients indicate $0.8 \%$ and $2.1 \%$ decrease in the expenditure share in "household utensils" is caused by $1 \%$ of price hike in "housing", "education, culture and recreation," respectively. However, a $2.3 \%$ increase in the expenditure share in "household utensils" is caused by $1 \%$ increase in price of "transportation and communication."

Compensated cross-price elasticity of demand for "housing-clothing," "housing-medical care," "housing-transportation and communication" and "housing-other expenditure" is 0.9101 , $-1.4610,1.7171$, and 2.5780, respectively. "Housing-clothing," "housing-transportation and communication," "housing-other expenditure" are net substitute goods. By implication, 1\% of price hike in each respective good like "clothing", "transportation and communication," "other expenditure" causes $0.9 \%, 1.7 \%$ and $2.6 \%$ of increase in the corresponding expenditure share in "housing." "Housing" and "medical care" are net complement goods, in which the expenditure share in "housing" decreases $1.5 \%$ when the price of "medical care" increases $1 \%$.

9 A negative value of compensated cross-price elasticity of demand means good $\mathrm{i}$ and good $\mathrm{j}$ are net complementary goods whereas a positive value means they are net substitute goods. A net complement means a good's demand decreases when the price of another increases (the reverse also holds). Conversely, a net substitute is when the demand of a good increases when the price of another good increases (the reverse also holds). 
Compensated cross-price elasticity of demand for "education, culture and recreation" with respect to "food," "transportation and communication," "other expenditure" is statistically significant, respectively. The elasticity of each pair of goods is $-0.4033,1.9364$, and 1.8159 , respectively. These estimated results suggest that "education, culture and recreation-food" are net complement goods on the one hand. "Education, culture and recreation" with respect to "transportation and communication," "other expenditure" are net substitute goods. The expenditure share in "education, culture and recreation" decreases $0.4 \%$ when the price of "food" increases $1 \%$. Conversely, the expenditure share in "education, culture and recreation" increases $1.9 \%$ and $1.8 \%$ when the respective price of "transportation and communication" and "other expenditure" increases $1 \%$.

It is worth noting that the substitution effects for "food-housing," "food-education, culture and recreation," "clothing-housing," "clothing-medical," "household utensils-transportation and communication," "housing-clothing," "housing-medical care," "housing-other expenditure," "education, culture and recreation-transportation and communication," "education, culture and recreation-other expenditure" and "other expenditure-transportation and communication" are positive. Theoretically, a substitution effect is assumed to be negative if marginal rate of substitution (MRS) is diminishing. For a substitution effect to take a positive value then it means MRS is increasing. This situation implies that there is an abundance of one good in each pair of goods. For example, because "food-housing" is a net substitute (i.e., $\gamma_{i j}^{c},>0$ ) therefore if the housing's price increases then the expenditure share of food increases. This substitution takes place where there is an abundance of food availability so that increase in consumption expenditure in "food" reduces its marginal utility but it causes the rise of marginal utility of the consumption expenditure in "housing." Similar explanation applies to all other pairs that are in this context.

Table 7 summarizes the relationship between good $\mathrm{i}$ and good $\mathrm{j}$ in terms of a net complementary good and a net substitute good.

Table 7: The relationship between good $\mathrm{i}$ and good $\mathrm{j}$ in compensated cross-price elasticity of demand

\begin{tabular}{ccccccccc}
\hline & $\mathbf{1}$ & $\mathbf{2}$ & $\mathbf{3}$ & $\mathbf{4}$ & $\mathbf{5}$ & $\mathbf{6}$ & $\mathbf{7}$ & $\mathbf{8}$ \\
\hline 1 & COPE* & - & - & Net sub. & - & Net comp. & Net sub. & Net comp \\
2 & - & COPE* & Net sub. & Net sub. & Net sub. & - & Net comp. & - \\
3 & - & - & - & Net comp. & - & Net sub. & Net comp. & \\
4 & - & Net sub. & - & COPE* & Net comp. & Net sub. & - & Net sub. \\
5 & - & - & - & - & - & - & - & - \\
6 & - & - & - & - & & - & - & - \\
7 & Net comp. & - & - & - & - & Net sub. & COPE** & Net sub. \\
8 & - & - & - & Net comp. & - & Net sub. & - & - \\
\hline
\end{tabular}

Notes: 1=food, 2=clothing, $3=$ household utensils, 4=housing, 5=medical care, $6=$ =transportation and communication, $7=$ education, culture and recreation, $8=$ other expenditure; Net sub. $=$ Net substitute good, Net comp. $=$ Net complementary good; $\mathrm{COPE}=$ compensated own-price elasticity of demand that is statistically significance; "**" and "**" denotes t-statistics at $1 \%$ and $5 \%$, respectively; "-"=statistically insignificance $\left(H_{0}: \gamma_{i j}^{c}=0, \forall i \neq j\right.$, ). 


\section{CONCLUSION}

Our empirical results reveal three characteristics. Firstly, the consumer behaviors in Changchun differ from the law of demand in three major expenditure items. "Food" and "education, culture and recreation" are necessity goods for the people in Changchun. The former constitutes $31.0 \%$ while the latter represents $13.2 \%$ of mean expenditure share, respectively. Both groups of goods comprise $44 \%$ of total expenditure share in our data set. At the same time, these two items are Giffen goods because their expenditure shares increase even with the rise in their prices. Similarly, the estimated income elasticity of demand for "housing" shows that although it is a luxury good, it is also a Giffen good because its expenditure share rises with the increase in its price. This can be interpreted that their real incomes are adjusted in terms of income effect in order to maintain same level of utility to offset the change in prices of the goods concerned. It is plausible to argue that the growth of real income across China in general and in Changchun in particular has been lagging behind the rise in prices of these three expenditure items.

Secondly, our estimated compensated cross-price elasticities of demand indicate that the theoretical assumption of a diminishing MRS does not hold for our data set. Based on these evidences, it is reasonable to contend that - in the case of Changchun-for the consumption expenditure shares in those net substitute goods, whereas consuming one good reduces its own marginal utility it increases the marginal utility of its substitute good.

Thirdly, expenditure share in "medical" is not influenced by the change in disposable income. Neither is this expenditure item affected by the change in its own price or prices of other goods (i.e., compensated own- and cross-price elasticities of demand are statistically insignificance). We contend that this phenomenon is the result of the government dominance of the medical/ healthcare sector in China. In other words, although the Chinese economic system is a marketbased one, it still has a relatively strong socialist characteristic particularly in the medical/ health sector. Most of the hospitals, clinics and medical/health facilities are state owned and publicly operated. As such, the supply of medical/health goods and services is constrained in spite of the continuous rise in income in the last few decades. As a consequence, our data set shows that people's demand in "medical" is not being influenced by its price and people's disposable income.

Our empirical analysis was based on the AR(1) for panel data with FE. We have considered autocorrelation in our specification because we have used CPI to deflate real monthly income in which prices for expenditure items also constituted in that index. Moreover, there was a massive fiscal expansion to counter recessionary pressure in China attributed to the world economic crisis caused by the Lehman collapse during the period of our data set (i.e., from January 2009 to December 2011). For this reason, our analysis would be more robust if it had incorporated structural variables in our specification. Although we understand this crucial issue, the time series for this panel data set is too short to permit such time variant analysis. These are the limitations in this empirical study.

In order to validate whether this case study applies to other urban areas in China, we need to conduct similar empirical inquiry for other Chinese cities, preferably with cities that are of higher and lower per capital income than Changchun. This will be our future study. 


\section{ACKNOWLEDGMENT}

The authors would like to thank a friend in Changchun who wishes to remain anonymous for his assistance in acquiring the household survey data, without which this empirical study would not have been possible.

\section{REFERENCES}

Alston, J. M., James, A. C., \& Piggott, N. E. (2002). Estimating and Testing the Compensated Double-log Demand Model. Applied Economics, 34, 1177-1186.

Barnett, W. A. (1979). Theoretical Foundations for the Rotterdam Model. The Review of Economic Studies, 46(1), 109-130.

Deaton, A., \& Muelbauer, J. (1980). An Almost Ideal Demand System. American Economic Review, 70(3), 312-326.

Fan, J. (2004). Diversity Research on Income Difference and Consumption Behavior of Rural Residents in China-Empirical Analysis Based on AIDS Model. Public Economic Theory. Paper presented at the Public Economic Theory (PET), Peking, China.

Greene, W. H. (2000). Econometric Analysis, Fourth Edition. Prentice Hall International, Inc.

Izumida, S., Ishi, H., Kimura, Y., \& Igarashi, T. (2006). Product Differentiation and Economic Analysis of Mergers (in Japanese). Japan: A Report for Japan Fair Trade Commission.

Koike, A. (2011). A Policy Analysis Based on Transport Elasticities Estimation by AIDS Model (in Japanese). Transport Policy Study (Unyu Seisaku Kenkyu), 14(3), 2-8.

Kruiniger, H. (2012). On the Estimation of Panel Regression Models with Fixed Effects. Queen Mary University of London, School of Economics and Finance Working Paper No 450.

Mitsubishi UFJ Research and Consulting. (2012). Shin Chuukan Sou Kakutoku Senryaku Ni Kansuru Kiso Teki Chousa (A Basic Research for the Strategy of Acquiring New Middle Class). Japan: Mitsubishi UFJ Research and Consulting Co., Ltd.

Nakano, S., Suzuki, M., \& Washizu, A. (2008). On the Ecological Effect of Changing in Our Consumption Behavior: A Simulation Analysis Using the Demand Function in the Semiflexible AIDS and the Environmental Input-Output Table (in Japanese). Journal of Life Cycle Assessment, 4(4), 367-376.

National Bureau of Statistics of China. (2011). Jilin Statistics Yearbook 2011. China, Jilin: China Statistics Press.

National Bureau of Statistics of China. (2013). China Statistics Yearbook 2013. China: China Statistic Press. 
Nolintha, V., \& Lau, S. Y. (forthcoming). Inequality in Laos and the Role of FDI. International Journal of Economic Policy in Emerging Economies.

Tachibanaki, T., \& Imayama, M. (1999). Changes in Consumer Behavior and Economic Development in East Asia (in Japanese). Japan: Ministry of Finance, Policy Research Institute.

Wakabayashi, M. (2001). Household's Preference Related with its Life Cycle Profile (in Japanese). Denryoku Keizai Kenkyu, 45, 17-34.

Ward, K., \& Neumann, F. (2012). Consumer in 2050: The rise of the EM Middle Class. London, United Kingdom: HSBC Global Economics Research Team.

Yang, T. (2009). Income Distribution and Household Consumption in China 2009 (in Chinese). China: China Economic Publishing House. 